\title{
A Cross-Cultural Study of Flow Experience in the IT Environment: The Beginning
}

\author{
Alexander E. Voiskounsky \\ Psychology Department, \\ Moscow State University \\ Russia \\ vaemsu@gmail.com
}

\begin{abstract}
Flow (optimal) experience is being widely investigated in the IT environments: in human-computer interaction, computer-mediated communication and exploratory behaviour, consumer and marketing applications, educational practice, playing computer, video and online games, psychological rehabilitation of the disabled, web usability testing, etc. Though a universal experience, flow can be expected to be culture specific and culture dependent. Optimal experience has only rarely been studied from a cross-cultural perspective, mainly in the field of gaming activities. An overview of the earliest works in the field is presented, as well as empirical evidences of a study referring to the flow experience and interaction patterns inherent to the samples of Russian and French online players.
\end{abstract}

Keywords: Optimal Experience, Flow, Interaction, Information Technologies, Culture, Online Games, Multy-Player Games, MUD, Cross-Cultural Study.

\section{Introduction}

Flow, or optimal experience, has been introduced by Mihaly Csikszentmihalyi. While interviewing dancers, chess players, rock climbers, surgeons and many others, he has selected often reported characteristics of a feeling which is related to what they believe constitute an optimal level of their experience. They produced almost identical verbal descriptions regardless of the particular sort of the preferred activity: 'being in the midst of a flow', or "flowing from one moment to the next" [1]. The interviewed people reported that at these moments they had been performing to the utmost. This sort of holistic experience was called flow, or else optimal experience [1].

Flow experience takes place when people are engaged in the preferred activity, including work, homework or hobbies, and is not likely to occur when they relax. Flow cannot be qualified as a regular attribute of one's engagement and absorption with the preferred activity; instead, every time it is a sort of a happening. Prior to experiencing flow, a person has to acquire competence in the preferred activity. Flow happens or not irrespectively of the nature of the activity itself. Processes of pursuing a desired result are reported to be more pleasing and self-rewarding that the result itself [1], [2]. From the fact that enjoyment is associated with the process of goal achievement, it can be concluded that repetitions of these processes are expected and wanted. 
Flow experience is presented manifold: as a high-level methodological construct applicable within/outside the field of psychology [2], [3], as a major factor of biocultural evolution and selection [3], [4], as a theory of creativity, good-work and development of talented adolescents [1], [5], as a developmental psychology theory [2], [6], as a cognitive artifact [1], [7], as a basis for psychological rehabilitation practice [4], [8], not to mention further. Also, the flow methodology has been successfully applied to diverse professions and occupations, including those that include the IT use.

\section{Characteristics of Flow Used in Empirical Research Projects}

The variety of flow related research in the IT environments includes learning to handle and adapt novel software and hardware pieces; online instruction and distant education; computer- and Internet-mediated communication; instant messaging and chatting; consuming web media sources and online entertainment; web marketing, eshopping, business web applications; online gaming, video gaming and playing computer games; web navigation, exploratory online behavior, search of content items on the web; illegal penetrations in the cyberspace field, in particular hacking; psychological rehabilitation by means of immersive virtual reality equipment and software; measurement of web-site attraction and friendliness, usability testing and adaptation of web sources to target populations. The whole line of research begins in the early 1990s [9].

Theoretically and empirically, Csikszentmihalyi [1], [2] has selected the following major characteristics of flow: clear and distinct goals; loss of self-consciousness; distorted sense of time; actions and awareness merge; immediate feedback; concentration on the task; high level of control over it; balance (precise matching) between the available skills and the task challenges; activity seems worth doing for its own sake. A recent paper [10] says that "these factors may not be the only ones that contribute to flow, but Csikszentmihalyi identifies them as the most commonly exhibited ones (p. 83)". Other researchers have made efforts to use more characteristics and to validate them. For example, some authors [11-13] found additional characteristics to accompany the known ones: for example, interest, discovery and curiosity, excitement, positive affects, time urgency, quality of computer interfaces, etc.

In an influential study [14] the model of flow experience in the IT environments was introduced; it included such characteristics as vividness and interactivity which cumulatively induce the parameter of (tele)presence, or "mediated perception of an environment" [14]; later the inclusion of additional characteristics (for example, presence and interactivity) into the revised model was empirically validated [15]. The inclusion of media-specific characteristics referring to the mediated environments seems a reasonable thing to do; for example, 'presence' was not once named by respondents in interviews and/or surveys [12], [13], [16].

Often specialists share the view that the flow dimensions may be variable, dependent on the particular type of activity human beings are engaged in. Thus, in order to qualify flow experience it is important that some of the dimensions are marked, not necessarily all of them. Indeed, a sensation of flow experienced while online shopping 
might be described with a set of characteristics only partly matching the parameters describing flow experienced while online gaming, or navigating the web, etc. As Rettie [17] states, "while respondents recognized most of Csikszentmihalyi's dimensions, the merging of action and awareness and loss of self-consciousness were not really relevant (p. 111)".

The sets of characteristics differ, taken for example less vs. more competent (in the same types of activities) respondents; with the change of activities, the levels of competence may become the opposite, as it often happens. Possibly there are sets of flow dimensions (or characteristics), which can be informally called "flow dialects"; these 'dialects' strongly depend on task specificity, competence in this or that task, emotional state, quality of computer/web interfaces, software applications, type of prior instruction, and probably on other parameters which have not yet become obvious.

Flow may be expected when the available skills match task challenges one chooses, provided both are close to the person's utmost. Precise matching means a perspective for personal growth. Such a balance is often adopted as an antecedent of flow [14], [18]; sometimes, however, it is not discovered as a significant parameter [16].

\section{Cross-Cultural Studies of Flow Experience in IT Environments}

\subsection{Culture Related Studies}

Traditionally, research projects in the optimal experience field include cross-cultural comparisons. Not so in the IT environments: little can be said about non-English and non-Taiwanese IT users. Some studies have been carried out within German students [19-21], Russian gamers and hackers [22-24], Korean online gamers [25], and Scandinavians - speakers of Norway [26], Swedish [27], [28], and Finnish [29]. Pioneer studies have also been carried out in Israel within groups chatting in Hebrew [30] and within a population of Brazilian journalists, active in the IT use [31]. Neither of these works is, nevertheless, comparative and might be qualified a cross-cultural study, although IT environments are global and intercultural. For many other ITrelated areas (for example, the digital divide, gender issues in e-shopping, attitudes towards IT, computer anxiety, etc.) the interest toward intercultural comparisons is significant.

Hopefully, the current lack of interest to cross-cultural specifics of flow experience in the IT environments will not last long. At the moment we are able to refer to a comparative investigation of flow patterns displayed while navigating through a marketing website; bilingual speakers of Spanish and English participated [32]. One of researchers' goals was to create a cross-cultural model of web related flow experience, and to trace the impact of several cultural factors (including for example within-site navigation using first or second language verbal skills) on attitudes toward the website and on participants' actual cognitive schemes; besides, marketing parameters were of interest: purchases from the e-shop and intentions to revisit it. 


\subsection{A Cross-Cultural Study of Optimal Experience While Playing MUDs}

Another research project will be described in more details; it is targeted on culture specific aspects of flow experience in samples of Russian and French online gamers. It has been planned as a cross-cultural work and consists of two independent studies administered under the equal methodology and procedure. Full reports are published: the study carried out within the sample of gamers speaking Russian [22], [23] and within the sample of gamers speaking French [33]. The study was held in collaboration with Dr. Olga Mitina and Ph.D. student Anastasiya Avetisova.

The cross-cultural research was planned and held within communities of MUD gamers - MUDs represent the earliest text-only version of the MMORPG class of games. Playing MUDs is a typically global activity; non-native speakers of English were involved in MUDding when there were no options to use a language other than English, but with years passing, various national-language scripts of MUDs became acceptable. MUD is a class of online games being continuously played since 1978 [34].

The reasons to compare the two particular samples of gamers - the French and the Russian - are as follows [35]. First, there are MUD servers and MUD players in both the countries (Russia and France); the two cultures exhibit neither particular prejudices nor particular sympathies toward online gaming. No prior research of flow experienced while playing MUD is known in any of these two countries.

Second, online speakers of French as well as online speakers of Russian include citizens of countries other than the two metropolitan states. The speakers of French (francophones) are located, besides France, in Canadian Quebec, in European countries neighboring France, and in French-speaking African countries; speakers of Russian are located, besides Russia, in post-Soviet countries (including the Ukraine, the population of which is close to that of the France), as well as in the USA, Israel, Germany, Australia and other countries. Since the speakers of the two languages are distributed, it is reasonable to suppose that the respective online populations are also distributed.

Third, we find parallels in the ways the two metropolitan countries became late in acquiring global access to the Internet: the Russians due to the totalitarian nature of the Soviet state for which free exchange of views was alien; the French due to the pioneer development of the videotex system Minitel. With time passing, the Minitel penetration is a barrier [35] to the advance of the Internet: "France was the first to develop a public telematic system", but "the French telematic system now appears outmoded (p. 37)".

Fourth, the two online audiences seem to be comparable in their amounts. Since no reliable statistics of MUD players is known, we can at best suppose that the two supposedly comparable online audiences contain a supposedly comparable number of gamers in general and finally a supposedly comparable number of MUD players. Thus, we have to compare the audiences by the time when research was held, 2003-2004.

First we estimate the Russian online audience. The reliable sociological bureau, the Foundation for Public Opinion (www.fom.ru) informs that by the end of 2003 the audience was equal to 13.1 M citizens of Russia, aged 18+. Thus, Russian-speaking non-citizen and younger generations - the two categories of frequent and competent 
users - stay outside the sociological survey. It is usually stated (see arguments at [36]) that at the time research was held the citizens of Russia formed a little more than half and certainly less than two thirds of the total online audience of speakers of Russian; the amount of children and adolescents before 18 on the Web is estimated as about a half of the adult audience. Thus, a rough estimation says the Russian online audience which includes non-citizens and teenagers, active in 2003, may be approximated as close to $30 \mathrm{M}$ (but not reaching this amount).

To estimate the online francophones audience, we take the data placed at the "Global Reach" (http://www.glreach.com/globstats/), classified by languages. Quoting the 2004 reference (http://global-reach.biz/globstats/refs.php3\#6) we get the following estimation:

There are 22.4 M people in France online (source: Nielsen/NetRatings, Feb., 2004). French-speaking Canada follows at $2.3 \mathrm{M}$ people online (according to The Daily Statistics (Canada), March, 2001. One must add 1.0 M French-speakers in Switzerland (23\% of the $4.3 \mathrm{M}$ Swiss online, according to Nielsen NetRatings marketing research, Feb., 2004). Among the 3.4 M people online in Belgium (see latest survey from $\underline{\mathrm{GfK}}$ and InSites), one-quarter of them, or $0.9 \mathrm{M}$, are from the French-speaking provinces. Next to Belgium, Luxembourg has $170 \mathrm{~K}$ people online (source: ITU, 2003). Another $95 \mathrm{~K}$ Americans who access the Internet in French $(50 \%$ of the French-speaking American population). (We will not count the Frenchspeaking users in Africa, although there are a good 7 to $10 \mathrm{M}$ Africans who speak French there: Internet access is simply not readily available in most African countries.) This gives a total of $33.3 \mathrm{M}$ French-speaking people online.

We conclude, by the time of cross-cultural study the francophone online audience outscored the Russian online audience by 10 per cent. Though this is a difference, we state that the two audiences are comparable and reasonably close. Supposedly, the populations of MUD players are comparable in approximately the same proportion as the online audiences. We compare the two populations of MUD players taken as a whole, i.e. irrespectively of the particular MUD-type games they use to play.

The cross-cultural methodology included the adaptation of the prior (Russian) questionnaire of 40 questions (including 8 questions on demography, on longevity and frequency of playing sessions) in order to get the French questionnaire culturally and linguistically equal. The procedure consisted of translating the Russian questionnaire into French; trial testing within a small sample of MUD gamers; putting questions to French speakers, not necessarily online gamers; inserting appropriate changes into the questionnaire to be adapted, and testing once more [33]. The data collecting procedure was that of an online survey, it was held in 2003 (Russian part) and 2004 (French part).

Analysis of research results includes [22], [23], [33] the analysis of respondents' demography and all the questionnaires' items, explorative and confirmatory factor analyses, comparative analysis of questionnaires' items, qualitative analysis of the factor models allocated to the Russian and the French samples. Since the current overview paper is not the full report of the comparative study, we do no more than 
describe the two factor models, referring to the Russian and the French samples, and correlations between the factors and the particular questionnaires' items.

The total number of participants is 347 speakers of Russian and 203 francophones. As anticipated, both samples included non-citizens of respectively Russia and France. Explorative factor analysis provided a six-factor model for the Russian sample [22], [23] and a three-factor model for the French sample [33]. The factors can be viewed at the Fig. 1, which provides correlations between factors and questionnaire items (non-demographic ones); the latter is loosely translated into English. Both factor models include the Flow factor; the models are significant, intercorrelations between the factors are reasonably high [22], [23], [33]. A brief discussion of the factor models follows.

The Russian factor model includes all the factors characterizing the French one: Flow, Achievement, Cognition and Interaction - the latter means social interaction, not between the user and the system [25]. Hence, factor models characterizing the Russian and the French samples are partly similar. Besides, in the factor model characterizing the Russian sample there are two more factors, namely Activity/ Passivity and Thoughtfulness/Spontaneity. In the French sample Interaction and Cognition merge, while for the Russians these represent independent factors. In a way, the Russian factor structure is more transparent: the four factors common for the two samples and characterizing prevalent gamestyles do not merge, unlike the factor structure of the French sample. On the other side, the French factor structure shows that in MUD games Cognition presupposes Interaction in the form of social perception, i.e. gaining knowledge about fellow players: thus, the merge of the two factors looks reasonable.

The analysis of the data at the Figure 1 presents a special perspective for discussion. One can easily notice that the French-sample major factor, i.e. Achievement, includes all the questionnaire items referring to the Russian-sample Achievement factor plus several additional parameters referring to Flow factor (mostly common to the Russian and the French samples). Thus, for the Frenchmen Achievement includes elements of Flow: 'focused attention', 'mobilization', and 'perception of reality' - the latter, we believe, may refer to 'presence'. In other words, the desire for Achievement, characteristic for the French sample, includes some standard characteristics of Flow. The Russian-sample desire for Achievement does not include characteristics alien to this desire. Also, for the Russians Achievement is not the first factor, unlike the French sample.

Thus, flow is a really significant component of online games, it turns out to be either the major factor (in the Russian sample) or included into the major factor as its important component (in the French sample). In the both samples flow is a significant factor. This outcome seems to be important both in the cross-cultural context, and in the context of the gamers' attitudes toward playing MUDs. That means, a probable reason for long-time devotion to MUDs (a sort of old-fashioned, i.e. text-only games without rich modern graphics) is that playing MUDs provokes flow experience, an expected feeling highly estimated by the players. This is shown to be true for at least two national samples of online gamers; the more reasons to investigate it in more samples and applied to a more diverse class of games, not necessarily MMORPG-like games. 


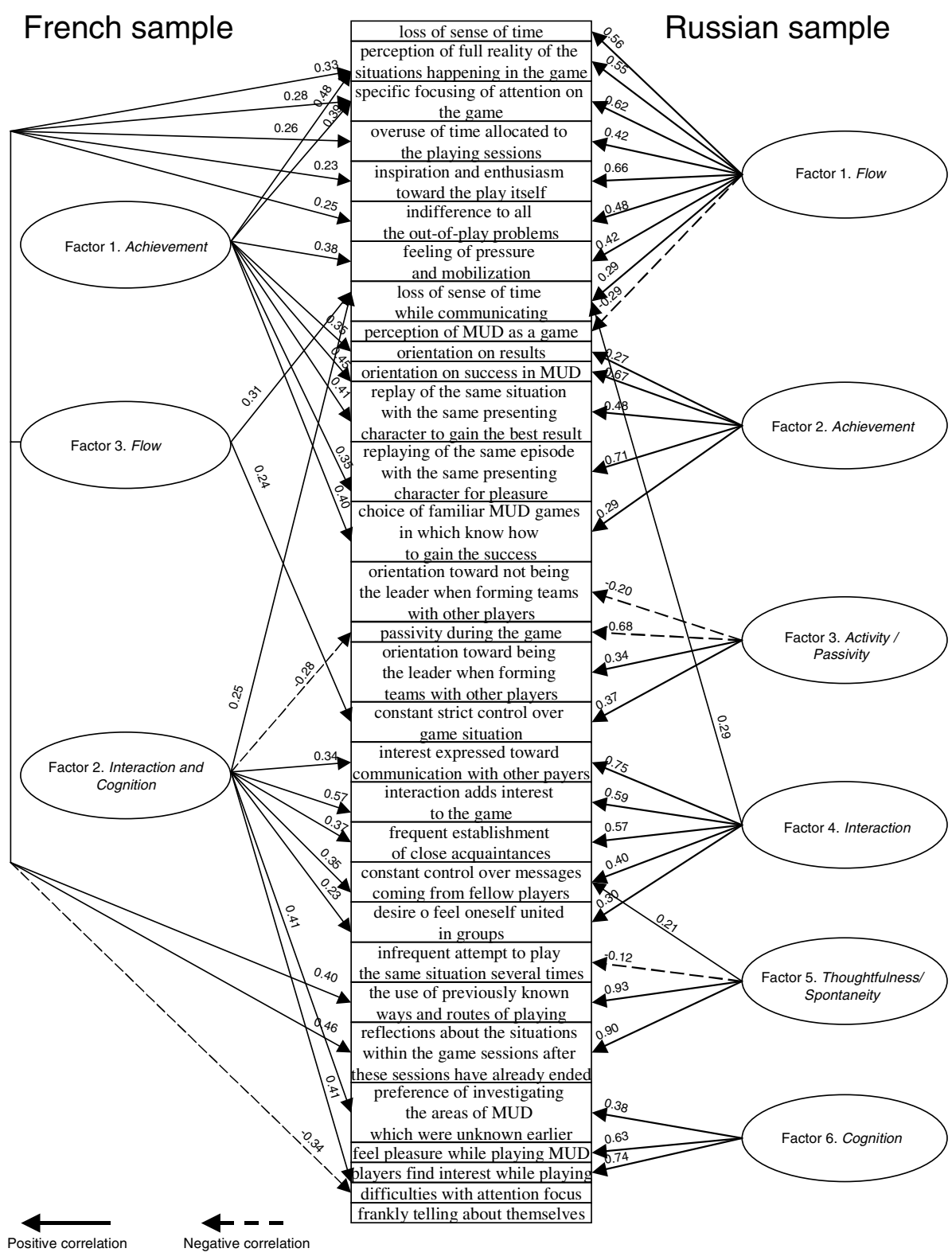

Fig. 1. Correlations between the factors and the questionnaire items (Russian and French samples)

Although thorough analysis of data gained in the two investigations (partly presented at the Figure 1) may provide more interesting findings, we will not go into further details of this cross-cultural study. We believe the importance of this type of investigation will be constantly increasing. 


\section{Conclusions}

Optimal, or flow experience represents an important parameter inherent of various IT related behaviors. For example, a possible explanation of players' years-long, if not decades-long attachment to text-only group roleplays like MUD is that they experience flow and are fond of the feeling. Dependent on task specificity, personal competence, type of prior instruction, and probably on other parameters which have not yet become obvious, there are what may be called "flow dialects", i.e. partly different sets of flow-related dimensions characterizing optimal experience. Although people experiencing flow have been identified in all the investigated cultures, and thus flow is universal, at the same time the particular characteristics of optimal experience are expected to be culture sensitive. This is supposedly true, taken IT related activities which are about the most universal types of activity. Very few culture related studies have been done in the field up to now; the available results confirm the conclusion that cross-cultural analysis of flow experience in the IT environments provides good perspectives for gaining new knowledge. For example, flow is a significant factor and at the same time it is differently located in the factor models characterizing the two investigated samples of players in online role games like MUDs: the sample of speakers of Russian and the sample of francophones.

Acknowledgments. Research was supported by the Russian Foundations for Humanities, project \# 06-06-00342a.

\section{References}

1. Csikszentmihalyi, M.: Beyond boredom and anxiety: Experiencing flow in work and play. Jossey-Bass, San-Francisco (first published in 1975) (2000)

2. Csikszentmihalyi, M.: Flow: The psychology of optimal experience. Harper and Row, New York, NY (1990)

3. Csikszentmihalyi, M.: The evolving self: A psychology for the third millennium. HarperCollins, New York, NY (1993)

4. Optimal experience: psychological studies of flow in consciousness. In: Csikszentmihalyi, M., Csikszentmihalyi, I.S. (eds.) Cambridge Univ. Press, New York, NY (1988)

5. Csikszentmihalyi, M.: Creativity. Flow and the psychology of discovery and invention. HarperPerennial, New York, NY (1996)

6. Csikszentmihalyi, M., Larson, R.: Being adolescent: Conflict and growth in the teenage years. Basic Books, New York, NY (1984)

7. Csikszentmihalyi, M.: Attention and the holistic approach to behavior. In: Pope, K.S., Singer, J.L. (eds.) The stream of consciousness, pp. 335-359. Plenum Press, New York, NY (1978)

8. Delle Fave, A., Massimini, F.: Bringing subjectivity into focus: Optimal experiences, life themes, and person-centered rehabilitation. In: Linley, P.A., Joseph, S. (eds.) Positive psychology in practice, pp. 581-597. Wiley \& Sons, Hoboken, NJ (2004)

9. Trevino, L.K., Webster, L.: Flow in computer-mediated communication. Communication research 19(5), 539-573 (1992) 
10. Finneran, C.M., Zhang, P.: Flow in computer-mediated environments: Promises and challenges. Communications of the Association for information systems 15, 82-101 (2005)

11. Chen, H.: Flow on the net - detecting web users' positive affects and their flow states. Computers in human behavior 22, 221-233 (2006)

12. Chen, H., Wigand, R.T., Nilan, M.S.: Optimal experience of web activities. Computers in human behavior 15(5), 585-608 (1999)

13. Pace, S.: A grounded theory of the flow experiences of web users. International journal of human-computer studies 60(3), 327-363 (2004)

14. Hoffman, D.L., Novak, T.P.: Marketing in hypermedia computer-mediated environments: Conceptual foundations. Journal of marketing 60(3), 50-68 (1996)

15. Novak, T.P., Hoffman, D.L., Duhachek, A.: The influence of goal-directed and experiential activities on online flow experiences. Journal of consumer psychology 13(12), 3-16 (2003)

16. Skadberg, Y.X., Kimmel, R.: Visitors' flow experience while browsing a web site: Its measurement, contributing factors and consequences. Computers in human behavior 20(3), 403-422 (2004)

17. Rettie, R.: An exploration of flow during Internet use. Internet research: Electronic networking applications and policy 11(2), 103-113 (2001)

18. Pearce, J.M., Howard, S.: Designing for flow in a complex activity. In: Masoodian, M., Jones, S., Rogers, B. (eds.) APCHI 2004. LNCS, vol. 3101, pp. 349-358. Springer, Heidelberg (2004)

19. Konradt, U., Filip, R., Hoffmann, S.: Flow experience and positive affect during hypermedia learning. British journal of educational technology 34(3), 309-327 (2003)

20. Konradt, U., Sulz, K.: The experience of flow interacting with a hypermedia learning environment. Journal of educational multimedia and hypermedia 10(1), 69-84 (2001)

21. Tzanetakis, R., Vitouch, P.: Flow-experience, the Internet and its relationship to situation and personality. Abstract of a paper presented at the Internet Research 3.0: Net/Work/Theory (Maastricht, The Netherlands) (2002) available at: http://aoir.org/2002/ program/tzanetakis.html

22. Voiskounsky, A.E., Mitina, O.V., Avetisova, A.A.: Playing online games: Flow experience. PsychNology journal 2(3), 259-281 (2004)

23. Voiskounsky, A.E., Mitina, O.V., Avetisova, A.A.: Communicative patterns and flow experience of MUD players. International journal of advanced media and communication 1(1), 5-25 (2005)

24. Voiskounsky, A.E., Smyslova, O.V.: Flow-based model of computer hackers' motivation. CyberPsychology \& behavior 6(3), 171-180 (2003)

25. Choi, D., Kim, J.: Why people continue to play online games: In search of critical design factors to increase customer loyalty to online contents. CyberPsychology \& behavior 7(1), 11-24 (2004)

26. Heidman, L., Sharafi, P.: Early use of Internet-based educational resources: Effects on students' engagement modes and flow experience. Behaviour \& information technology 23(2), 137-146 (2004)

27. Montgomery, H., Sharafi, P., Heidman, L.R.: Engagement in activities involving information technology: Dimensions, modes, and flow. Human factors 46(2), 334-348 (2004)

28. Sharafi, P., Heidman, L., Montgomery, H.: Using information technology: Engagement modes, flow experience, and personality orientations. Computers in human behaviour 22(5), 899-916 (2006) 
29. Pilke, E.M.: Flow experiences in information technology use. International journal of human-computer studies 61(3), 347-357 (2004)

30. Shoham, A.: Flow experiences and image making: An on-line chat rooms ethnography. Psychology and marketing 21(10), 855-882 (2004)

31. Manssour, A.B.B.: Flow in journalistic telework. CyberPsychology \& behavior 6(1), 31-39 (2003)

32. Luna, D., Peracchio, L.A., de Juan, M.D.: Cross-cultural and cognitive aspects of web site navigation. Journal of the academy of marketing science 30(4), 397-410 (2002)

33. Voiskounsky, A.E., Mitina, O.V., Avetisova, A.A.: Flow experience and interaction: Investigation of francophone online gamers. In: Sudweeks, F., Hrachovec, H., Ess, C. (eds.) Cultural attitudes towards technology and communication. Proceedings, 5th international conference, Tartu, Estonia, 28 June - July, pp. 385-396. School of information technology, Murdoch University, Murdoch, Australia (2006)

34. Bartle, R.: Designing virtual worlds. New Riders Publishing, Indianapolis, IN (2003)

35. Lemos, A.: The labyrinth of Minitel. In: Shields, R. (ed.) Cultures of Internet: Virtual spaces, real histories, living bodies, pp. 33-48. Sage, New Delhi, Thousand Oaks, London (1996)

36. Voiskounsky, A.: Internet culture in Russia. Internet-based teaching and learning (INTELE) 99. In: Proceedings of IN-TELE 99 conference. Frankfurt a/M: Peter Lang, pp. 36-44 (2001) 